Please send trade news information and illustrations to Arveen Bajaj at the BDJ, 64 Wimpole Street, London W1G 8YS. Trade news is supplied as a service to the reader and does not imply endorsement by the BDJ. Normal and prudent research should be exercised before purchase of use of any product mentioned.

\section{One piece implant}

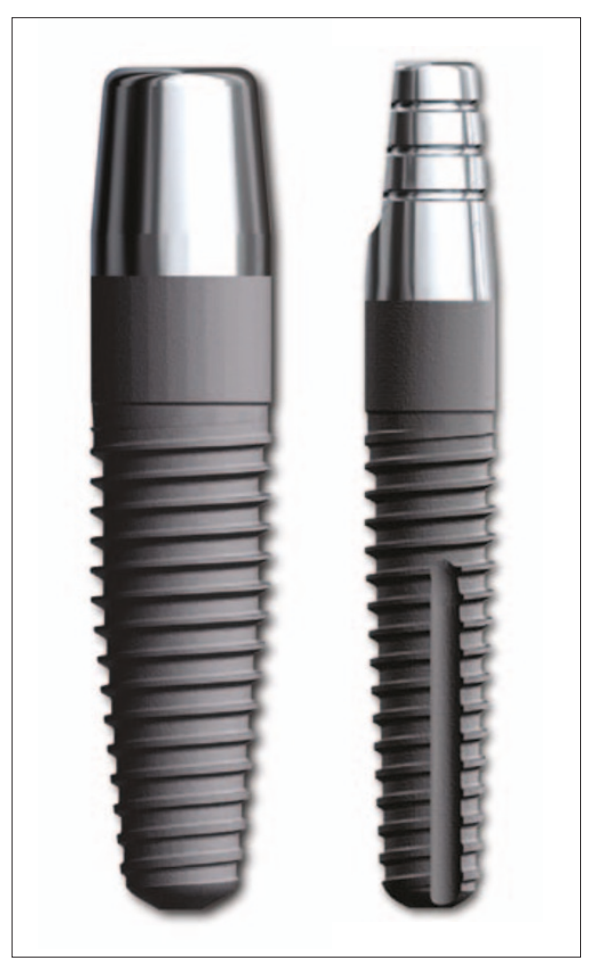

Nobel Biocare have introduced a new one piece implant. The implant mimics natural teeth and is indicated for use in both single and multiple sites throughout the mouth.

It is machined from a single bar of titanium, incorporating both the implant body and an integral fixed abutment in one piece. The body of the implant is based on the Replace Select Tapered implant and is available in various lengths and diameters in both a scalloped and non-scalloped format. A special 3.0 diameter intended for tight-space challenges is also available.

According to Nobel Biocare, the surgery can be made flapless with minimal surgical invasion and far less discomfort for the patient and also means ease of placement for the dentist.

In addition it features the TiUnite surface, which ensures unsurpassed initial stability as well as long term osseointegration. The surface extends above the aveolar crest on the implant supporting the formation of a normal biological width. Reader response number 51

\section{TRADE NEWS}

WHAT'S NEW

\title{
Fresh breath
}

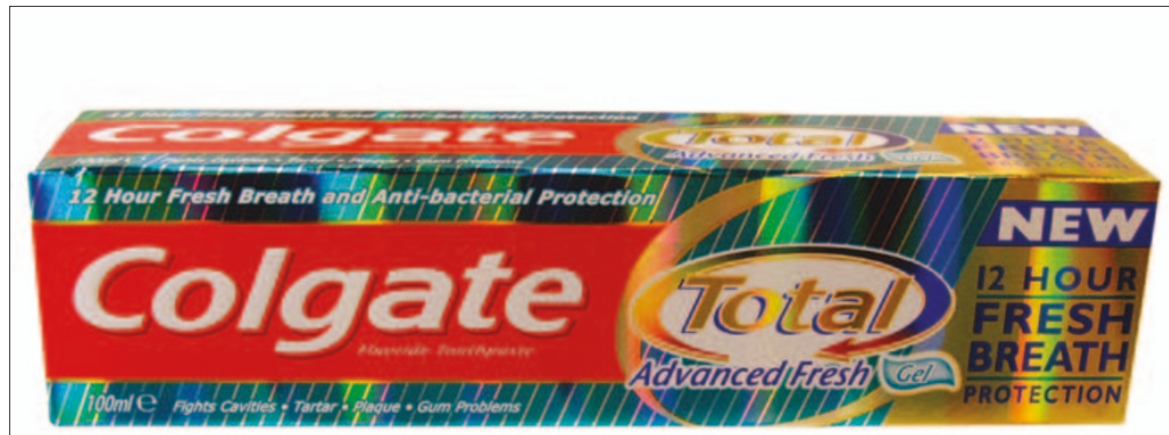

Colgate claims its new Colgate Total Advanced Fresh toothpaste has long lasting antibacterial protection which significantly reduces halitosis for up to 12 hours.

Its features include protection against cavities and improvement in gingival health due to a reduction in plaque and calculus formation, according to the company.

Reader response number 50

\section{New tool for communication}

Ivoclar Vivadent has produced the Tooth Communicator, a marketing tool which it suggests can be used at all levels of the communication process.

The Tooth Communicator includes 10 sets of selected Ivoclar Vivadent tooth moulds, including new BlueLine, SR Vivodent PE and SR Antaris tooth ranges. It is offered at an introductory price of $£ 44.95+$ VAT.

Reader response number 52

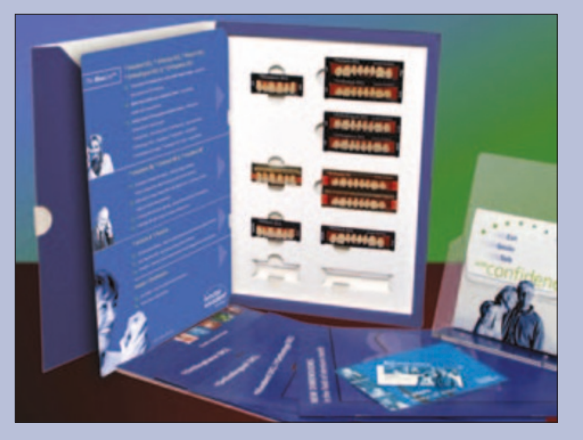

\section{Special offer available}

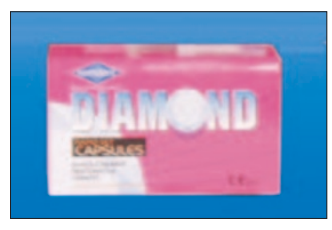

Kemdent have introduced a special offer on two of its products. New customers can receive a free trial pack of Diamond Snappy glass ionomer when they buy two packs of Diamond Snappy, or receive a free trial pack of Diamond rapid set GIC capsules when they buy two single packs of capsules. The trial packs are worth $£ 25$. According to Kemdent, Diamond Snappy has no unpleasant aftertaste, needs no primer or bonding agent, adheres to dentine and enamel, releases fluoride and is resistant to saliva as soon as the cavity is filled. It also contains no additional pigments and is available in a natural white shade.

Diamond rapid set capsules are chemical set and have a working time of 135 seconds from activation, build up fillings and linings and have a waterproof snap set. They are available in single packs of 20 capsules and value packs of 60 capsules, in shades A1, A3 and B3. The offer ends on 31 May.

Reader response number 53 


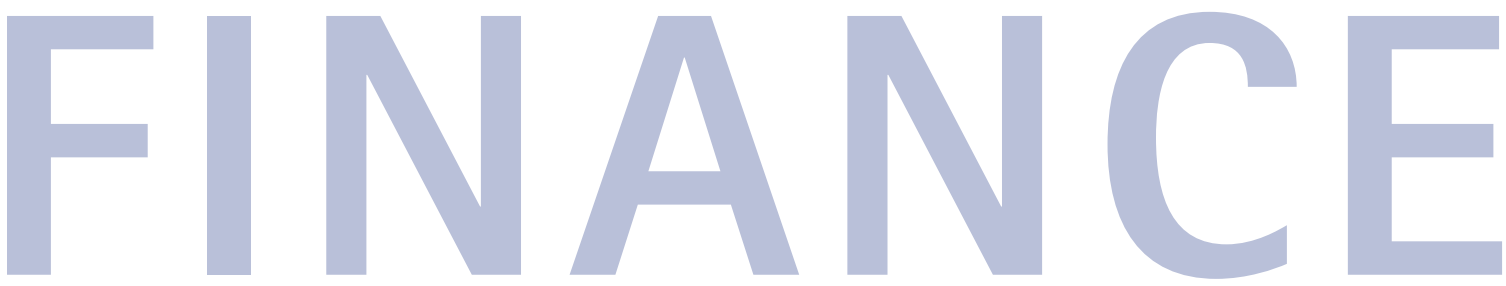

\section{Financial advice}

According to dental finance firm money4dentists, it can advise on specific issues as they arise, or practices can work alongside a financial planner on an ongoing basis.

An adviser can discuss the various investment options available for how and where to save and invest money and can also help identify priorities and objectives and then implement a plan to achieve those goals.

Its goal is to work closely with dentists to develop their own individual finance programme. For information visit www. money4dentists.com.

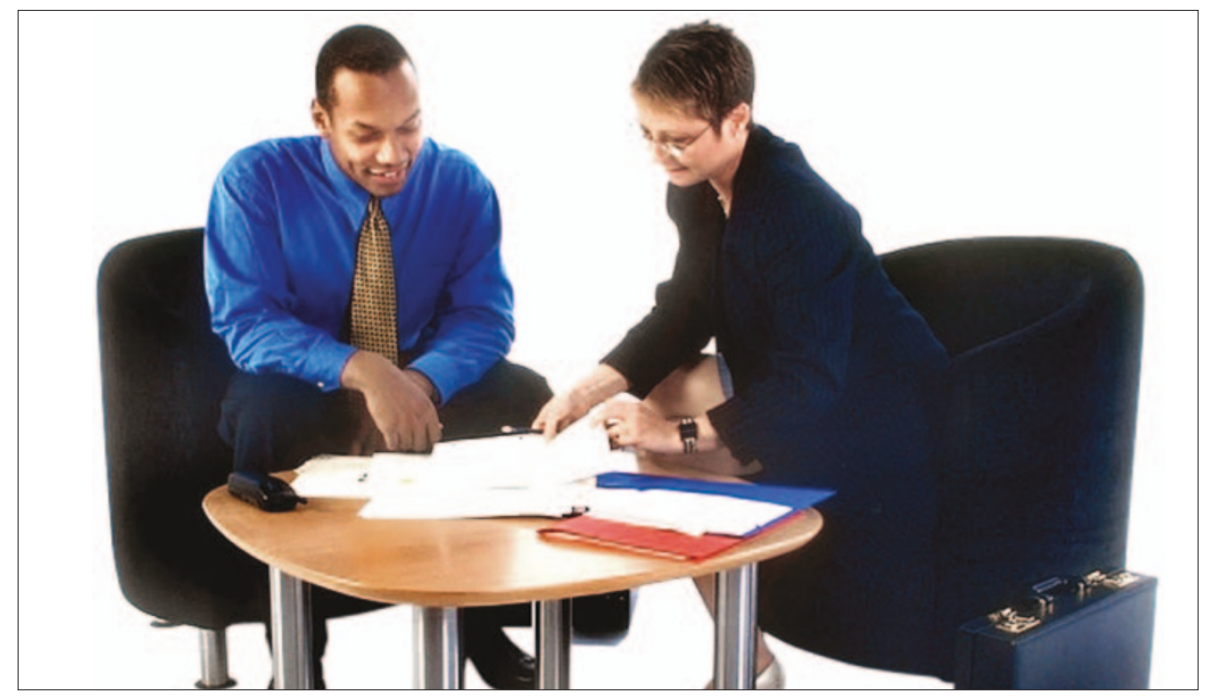




\section{Scanning technology}

A new enhancement to Software of Excellence's EXACT version 8, provided in conjunction with DentalShop, can help selling products easier, its manufacturers claim.

A hand held scanner is attached to the reception PC. The product can be simply scanned at the point of sale and the sale is billed by EXACT and restocking requirements automatically emailed to DentalShop every week or month.

DentalShop tailor your selection of items based on your stock movement and experience with like practices. The administrative task of re-ordering is taken away as DentalShop automatically replenish stocks to your optimum level.

Reader response number 55
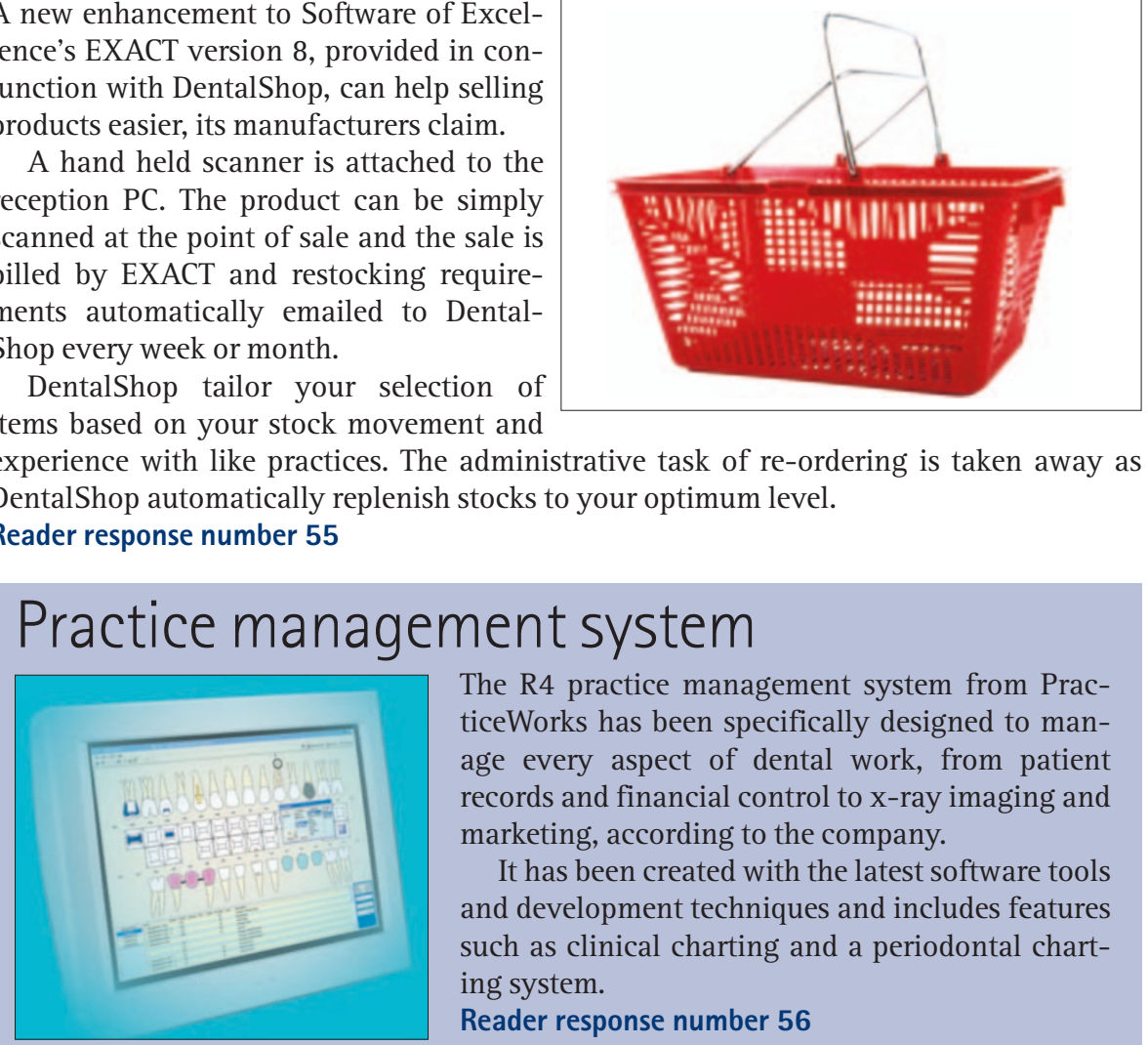

The R4 practice management system from PracticeWorks has been specifically designed to manage every aspect of dental work, from patient records and financial control to $\mathrm{x}$-ray imaging and marketing, according to the company.

It has been created with the latest software tools and development techniques and includes features such as clinical charting and a periodontal charting system.

Reader response number 56

\section{Sales and valuations}

Frank Taylor Associates can provide a range of financial services across the dental spectrum, including practice valuations, practice purchases, practice sales, 3dee patient treatment funding, an independent funding service and consultancy.

Its team can provide independent, comprehensive, objective and accurate valuations contained in a detailed and personalised report. It involves a visit to the practice for a first hand appreciation.

Each practice is also compared to other, similar practices and its valuation is related to the prices they realised when sold. Reader response number 57

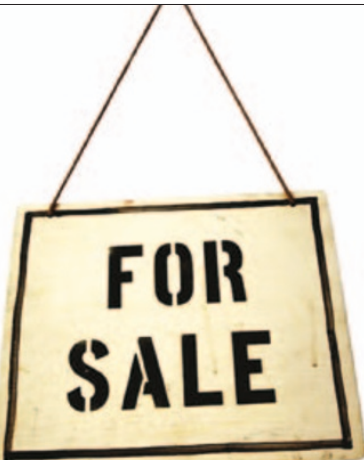




\section{Promoting private patient schemes}

Practice Plan claims it can help practices to promote private patient schemes starting with Plan Implementation through to introductory letters to patients.

Practice Plan will help compose letters to existing private patients promoting the benefits of the plan. Alternatively, if an NHS conversion is planned, it can help design letters to NHS patients giving the required three months' notice that the practice is moving into the private sector.

The Practice Plan Practice Development Manager will visit the practice and deliver a two to three hour training session geared to the practice's specific requirements. It will cover the benefits of the new plan for both patients and practice, issues relating to conversion from the NHS and all administration procedures and paperwork.

The company can provide personalised practice brochures, dentist/patient agreements, practice posters, recruitment cards, newsletters and advice and support on specific marketing procedures. The literature is either specific to the practice or generic. Reader response number 58

\section{Gold and silver service}

3dee Treatment Funding is a new payment scheme which allows patients to spread the cost of their dental treatments over a period of time that suits them.

According to 3 dee, it offers credit terms at lower interest rates than many loans, store cards or credit cards and practices can

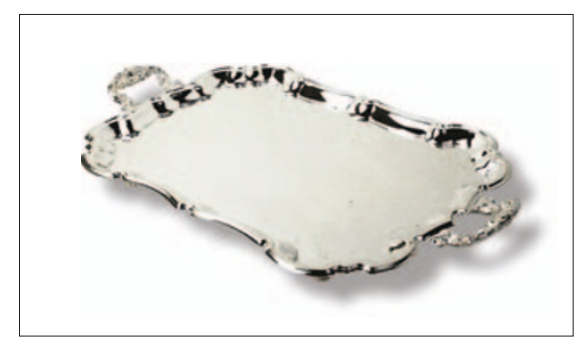

\section{Managing finances}

Henry Schein recently launched Henry Schein Financial Services offering a range of products. The First Product Brand Available is ChoiceHealth Leasing and has been created to provide dental practices with options in the way they manage their finances and fund major practice expenditure. It offers the choice of leasing, lease purchasing, hire purchase and borrowing.

According to the company, the Henry Schein team can help find the most cost efficient and tax efficient way of funding practice equipment purchases, ensuring highly competitive rates and the maximum tax relief.

Reader response number 60

determine their own interest rate for 3dee by choosing to subsidise the rate of interest they wish.

The range available is from $0 \%$ to $16.9 \%$, chosen at the discretion of the participating dentist. Frank Taylor Associates offers two levels of service, designated Silver or Gold. Silver Service includes all the necessary information and material to establish 3dee, including a training guide. The Gold Service adds to the Silver Service a full day's training at the practice and 3dee implementation. The additional fee is refunded when a 3dee level of $£ 30,000$ is achieved.

Reader response number 59

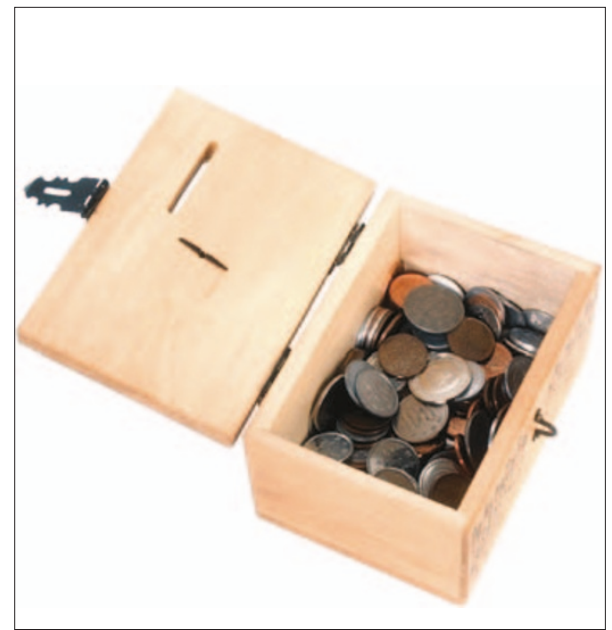

